\begin{tabular}{|c|c|c|c|}
\hline \multirow{3}{*}{$\begin{array}{r}\text { Case Reports in } \\
\text { Gastroenterology }\end{array}$} & \multirow{2}{*}{\multicolumn{2}{|c|}{ Case Rep Gastroenterol 2017;11:389-395 }} & \multirow[b]{3}{*}{$\begin{array}{l}\text { Karger } \\
\text { Open access }\end{array}$} \\
\hline & & & \\
\hline & $\begin{array}{l}\text { DOI: } 10.1159 / 000475749 \\
\text { Published online: June 15, } 2017\end{array}$ & $\begin{array}{l}\text { (C) } 2017 \text { The Author(s) } \\
\text { Published by S. Karger AG, Basel } \\
\text { www.karger.com/crg }\end{array}$ & \\
\hline & $\begin{array}{l}\text { This article is licensed under } \mathrm{t} \\
\text { International License (CC BY-NC } \\
\text { Usage and distribution for comm }\end{array}$ & $\begin{array}{l}\text { mons Attribution-NonCommercial } 4.0 \\
\text { rger.com/Services/OpenAccessLicense). } \\
\text { quires written permission. }\end{array}$ & \\
\hline
\end{tabular}

\title{
Gallstone Ileus: An Unlikely Cause of Mechanical Small Bowel Obstruction
}

\author{
Estela Abich Daniel Glotzer Edward Murphy \\ Florida State University College of Medicine, Fort Pierce, FL, USA
}

\section{Keywords}

Gallstone ileus · Intestinal obstruction · Pneumobilia · Enterolithotomy · Cholecystoduodenal fistula

\begin{abstract}
Gallstone ileus is a rare disease that accounts for $1-4 \%$ of intestinal obstructions. Almost exclusively a condition in the older female population, it is a difficult diagnosis to make. We report the case of gallstone ileus in a 94-year-old Caucasian female, who presented to the emergency department with acute-onset nausea, coffee-ground emesis, lack of bowel movement, and abdominal distension. On CT scan, the diagnosis of gallstone ileus was made by the presence of a cholecystoduodenal fistula, pneumobilia, and small bowel obstruction. Emergent laparotomy with a one-stage procedure of enterolithotomy and stone removal by milking the bowel distal to the stone were performed. The postoperative course was uneventful until postoperative day 4 when the patient was found tachycardic, lethargic, and unresponsive. We reviewed the literature on the diagnosis and treatment of gallstone ileus.

(C) 2017 The Author(s)

Published by S. Karger AG, Basel
\end{abstract}

\section{Introduction}

The most common causes of mechanical small bowel obstruction are postoperative adhesions and hernias. Other etiologies of small bowel obstruction include disease intrinsic to 
the wall of the bowel such as tumors or stricture and processes that cause intraluminal obstruction such as intussusception, gallstones, and foreign bodies [1]. A gallstone-induced mechanical obstruction of the small bowel is known as "gallstone ileus." Gallstone ileus is a rare complication of cholelithiasis [2]. It accounts for 1-4\% of all cases of mechanical intestinal obstruction, but up to $25 \%$ of the cases are comprised of patients over 65 years of age with a female:male ratio of 3.5-6:1 [3-6]. The morbidity and mortality of gallstone ileus remain remarkably high, most likely due to misdiagnosis and delayed diagnosis [7]. Early diagnosis and prompt treatment can reduce the mortality rate. Here we report a case of gallstone ileus and review the literature of this rare disease.

\section{Case Presentation}

A 94-year-old woman presented to the emergency department with acute onset of nausea, 5 episodes of coffee-ground emesis, lack of bowel movement, and abdominal distension. During the interview in the emergency department, she had 3 more episodes of coffeeground emesis. The patient had a past medical history of atrial fibrillation, coronary artery disease, congestive heart failure, hypertension, and COPD. Her past surgical history included an appendectomy, hysterectomy, tonsillectomy, and bilateral total knee replacements. The patient had dementia; therefore, all her history was obtained from her son and her medical records. Her son reported no alcohol or NSAID use. Laboratory values were remarkable for Na 132, K 4.1, glucose 162, WBC 16.5, with a left shift, and lactic acid 4.2 (Fig. 1). CT scans showed dilation of the stomach and proximal small bowel to the level of the proximal jejunum with air-fluid levels, communication between a collapsed gallbladder and the second part of the duodenum with associated pneumobilia consistent with cholecystoduodenal fistula, and a large $(2.4 \mathrm{~cm})$ calcified stone within the proximal jejunum, findings consistent with gallstone ileus (Fig. 2, Fig. 3). She was referred to surgery for emergent laparotomy. Under general anesthesia, a periumbilical incision was performed. Upon entering the abdomen, the small bowel was visibly dilated proximally. A loop of proximal jejunum was brought into the operative field and ran distally; we were able to very quickly get to the point of the obstruction which clearly showed a gallstone in the lumen of the jejunum that appeared to be at least $2.5 \mathrm{~cm}$ to approximately $3 \mathrm{~cm}$ in size blocking the lumen of the jejunum. The lumen itself was healthy and viable with no evidence of ischemia. This loop of bowel was brought out of the abdomen, and two stay sutures were placed on either side. Then an enterotomy was made just proximal to the area of obstruction, and the gallstone was milked proximally and removed. The enterotomy was closed in two layers. The bowel was placed back into the abdomen, and a general survey of the abdomen was performed during which no evidence of malignancy was found. The fistula was not repaired. The patient tolerated the procedure well. The final pathology of the specimen was reported as a gallstone: $11.5 \mathrm{~g}$, olive green-black colored, ovoid shaped, finely granular calculus that measured $2.9 \times 2.7 \times 2.5 \mathrm{~cm}$ (Fig. 4). The postoperative course was uneventful until postoperative day 4 when the patient was found tachycardic and unresponsive. Leukocytosis and subsequent chest X-ray revealed new right base infiltrate due to possible aspiration, and she developed AKI with no prior history of CKD. The patient deteriorated rapidly and passed away on postoperative day 6. 


\section{Discussion}

Gallstone disease is common, with a prevalence of $10 \%$ in the adult population in the USA [8]. Common complications of gallstone disease include acute cholecystitis, acute pancreatitis, choledocholithiasis with or without ascending cholangitis, and a gangrenous gallbladder. All these complications are heralded by notable clinical signs that allow clinicians to make prompt diagnoses and treatment plans. Other uncommon complications that are not so easy to diagnose include Mirizzi syndrome, cholecystocholedochal fistula, and gallstone ileus [2]. It is important to note, however, in a surgical series which included 5,673 cholecystectomies that 327 patients (5.7\%) had Mirizzi syndrome and 105 of these patients had a cholecystoenteric fistula. Of the patients who had a cholecystoenteric fistula, $90 \%$ had Mirizzi syndrome. Thus, the presence of a cholecystoenteric fistula should also include Mirizzi syndrome in the differential diagnosis.

In 1654, Bartholin first named gallstone ileus and defined it as a mechanical obstruction due to impaction of one or more large gallstones within the gastrointestinal (GI) tract. A gallstone can enter the GI tract through a fistula between an inflamed, most commonly gangrenous gallbladder and the GI tract. Pressure necrosis by the gallstone against the biliary wall then causes erosion and fistula formation. Reisner and Cohen [5] reviewed 1,001 cases of gallstone ileus and reported that the most common locations of gallstone impaction are the terminal ileum and the ileocecal valve because of the anatomical small diameter and less active peristalsis. Other rare locations of impaction include the jejunum, the ligament of Treitz, stomach, and far less commonly the duodenum and colon [5].

Clinical features of gallstone ileus are variable but can classically present in an older woman with episodic subacute obstruction known as "tumbling obstruction." This is a result of the stone quite literally tumbling through the bowel lumen with transient gallstone impaction causing diffuse abdominal pain and vomiting. The symptoms resolve only to recur as the stone lodges in a more distal bowel lumen, classically the terminal ileum or ileocecal valve. As a result, clinicians can receive a vague picture of symptoms that have been present for days prior to evaluation. On physical examination, the patient may be febrile and appear dehydrated. Common abdominal signs include abdominal distension and hyperactive bowel sounds [4]. The biochemical abnormalities are also nonspecific but can include leukocytosis, electrolyte imbalance due to dehydration, and elevated aminotransferase levels [4].

The diagnosis of gallstone ileus is challenging, and in suspected patients abdominal imaging is usually needed to confirm the diagnosis. Rigler's triad, described by Leo George Rigler in 1941, is a combination of radiological findings specific for bowel obstruction by gallstones [9]. It includes mechanical obstruction, pneumobilia, and an ectopic gallstone within the bowel lumen [9]. Our patient had all three Rigler's findings in the CT examination. Plain abdominal films are usually nonspecific because significant calcification of the stone is necessary in order for it to be visualized radiographically. Abdominal US is useful to confirm the presence of cholelithiasis and may identify a fistula if present [10]. Abdominal CT is the best modality in diagnosing gallstone ileus because of its better resolution, and a study by $\mathrm{Yu}$ et al. [11] concluded that CT also offers information for a decision-making strategy and subsequent surgical planning. Lassandro et al. [12] compared the clinical value of plain abdominal film, abdominal US, and abdominal CT in diagnosing 27 cases of gallstone ileus and found that Rigler's triad presents $14.8 \%$ in plain abdominal film, $11.11 \%$ in abdominal US, and $77.78 \%$ in abdominal CT.

Emergency surgery is required once the diagnosis of gallstone ileus has been made. Enterotomy with stone extraction alone remains the most popular operative method [13]. Non- 
surgical treatment of gallstone ileus has been suggested, including endoscopic removal and shockwave lithotripsy, but this depends on the location of the obstruction [14]. Furthermore, the prognosis of gallstone ileus is poor and worsens with age. Previous studies reported that the mortality rate is $7.5-15 \%[5,6]$ largely due to delayed diagnosis and concomitant conditions such as cardiorespiratory disease, obesity, and diabetes mellitus. We believe that our patient's comorbid conditions played a major role in her subsequent deterioration postoperatively.

In conclusion, gallstone ileus is a rare cause of intestinal obstruction. It must be considered in intestinal obstructions especially in older female patients with a history of gallstone disease. Abdominal CT is the preferred modality because of its rapid diagnosis and better resolution when compared to plain abdominal films and abdominal US. Surgical treatment is emergent once the diagnosis of gallstone ileus has been made.

\section{Statement of Ethics}

Informed consent was received from the patient.

\section{Disclosure Statement}

The authors of this case report declare that there are no conflicts of interest.

\section{References}

1 Harris J, Evers M: Small intestine; in Townsend C, Beauchamp RD, Evers B, Mattox K (eds): Sabiston Textbook of Surgery, ed 20. Philadelphia, Elsevier Saunders, 2016, chapt 49.

2 Abou-Saif A, Al-Kawas FH: Complications of gallstone disease: Mirizzi syndrome, cholecystocholedochal fistula, and gallstone ileus. Am J Gastroenterol 2002;97:249-254.

- 3 Kurtz RJ, Heimann TM, Kurtz AB: Gallstone ileus: a diagnostic problem. Am J Surg 1983;146:314-317.

4 Clavien PA, Richon J, Burgan S, Rohner A: Gallstone ileus. Br J Surg 1990;77:737-742.

5 Reisner RM, Cohen JR: Gallstone ileus: a review of 1,001 reported cases. Am Surg 1994;60:441-446.

-6 Rodríguez Hermosa JI, Codina Cazador A, Gironès Vilà J, Roig García J, Figa Francesch M, Acero Fernández D: Gallstone ileus: results of analysis of a series of 40 patients (in Spanish). Gastroenterol Hepatol 2001;24:489-494.

7 Lobo DN, Jobling JC, Balfour TW: Gallstone ileus: diagnostic pitfalls and therapeutic successes. J Clin Gastroenterol 2000;30:72-76.

8 Everhart JE, Khare M, Hill M, Maurer KR: Prevalence and ethnic differences in gallbladder disease in the United States. Gastroenterology 1999;117:632-639.

-9 Sahsamanis G, Maltezos K, Dimas P, Tassos A, Mouchasiris C: Bowel obstruction and perforation due to a large gallstone. A case report. Int J Surg Case Rep 2016;26:193-196.

10 Lasson A, Lorén I, Nilsson A, Nirhov N, Nilsson P: Ultrasonography in gallstone ileus: a diagnostic challenge. Eur J Surg 1995;161:259-263.

11 Yu CY, Lin CC, Shyu RY, et al: Value of CT in the diagnosis and management of gallstone ileus. World J Gastroenterol 2005;11:2142-2147.

-12 Lassandro F, Gagliardi N, Scuderi M, Pinto A, Gatta G, Mazzeo R: Gallstone ileus analysis of radiological findings in 27 patients. Eur J Radiol 2004;50:23-29.

-13 Halabi WJ, Kang CY, Ketana N, et al: Surgery for gallstone ileus: a nationwide comparison of trends and outcomes. Ann Surg 2014;259:329-335.

-14 Dumonceau JM, Delhaye M, Devière J, Baize M, Cremer M: Endoscopic treatment of gastric outlet obstruction caused by a gallstone (Bouveret's syndrome) after extracorporeal shock-wave lithotripsy. Endoscopy 1997;29:319-321. 

www.karger.com/crg

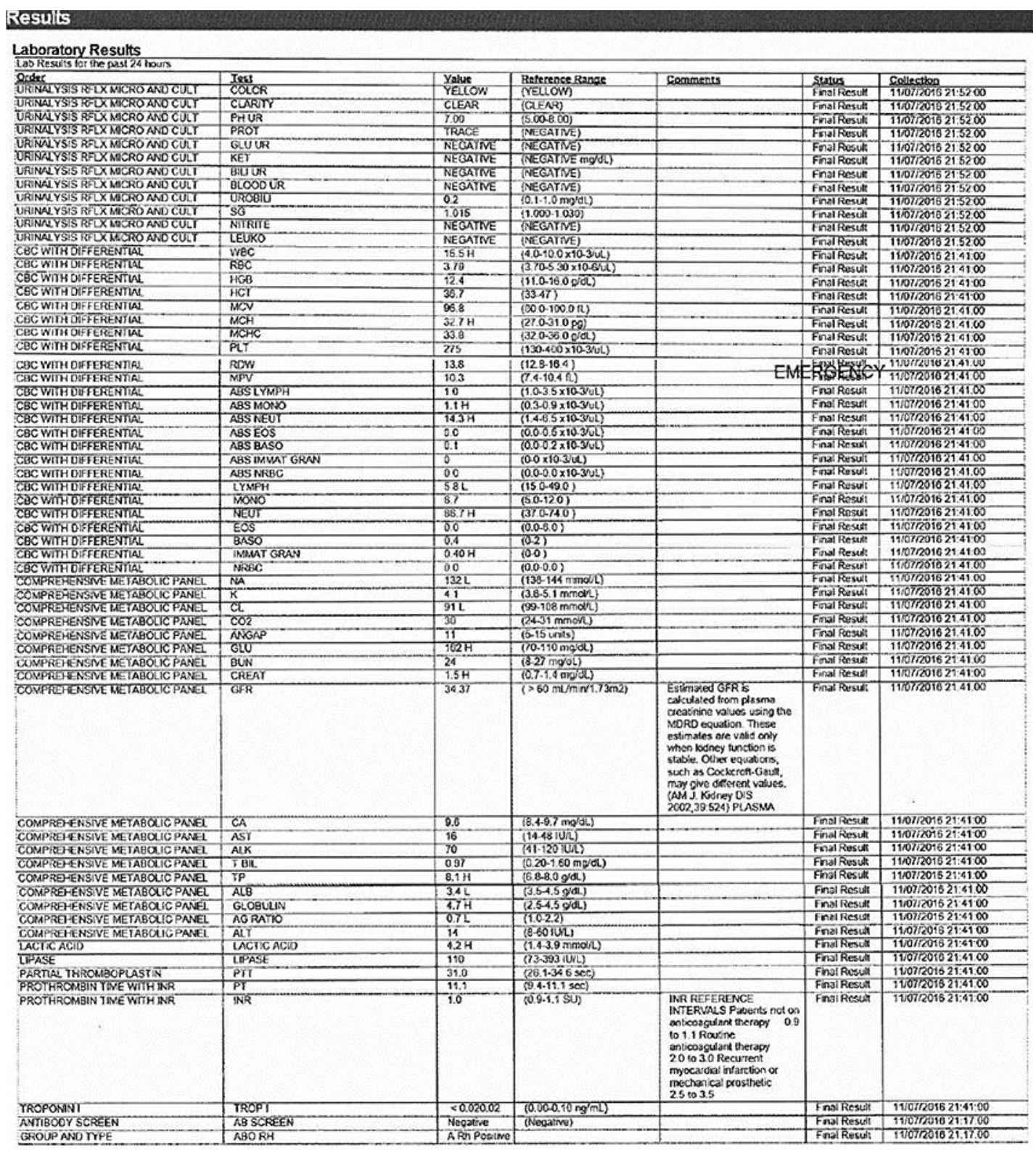

Fig. 1. Laboratory results on initial presentation to the emergency department. 


\section{Case Reports in Gastroenterology

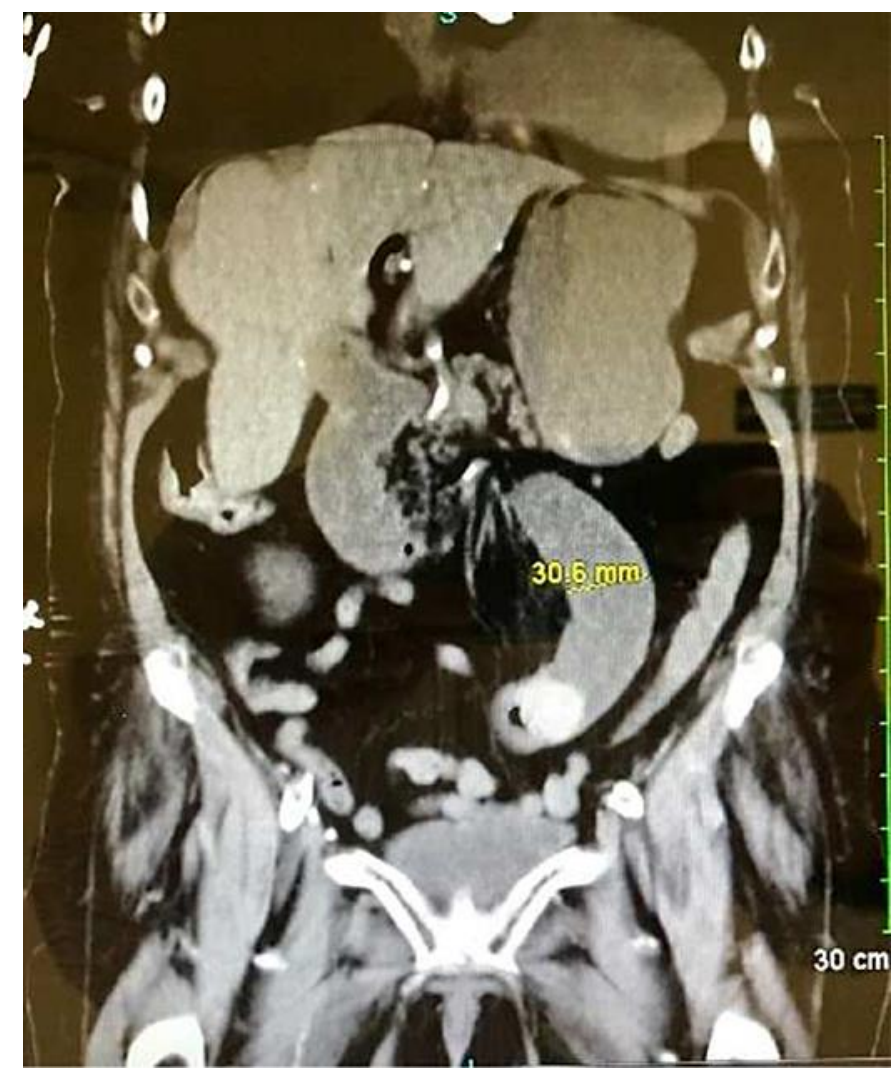

Fig. 2. CT scan showing cholecystoenteric fistula, calcification of the celiac trunk, and calcification of the gastroduodenal artery.
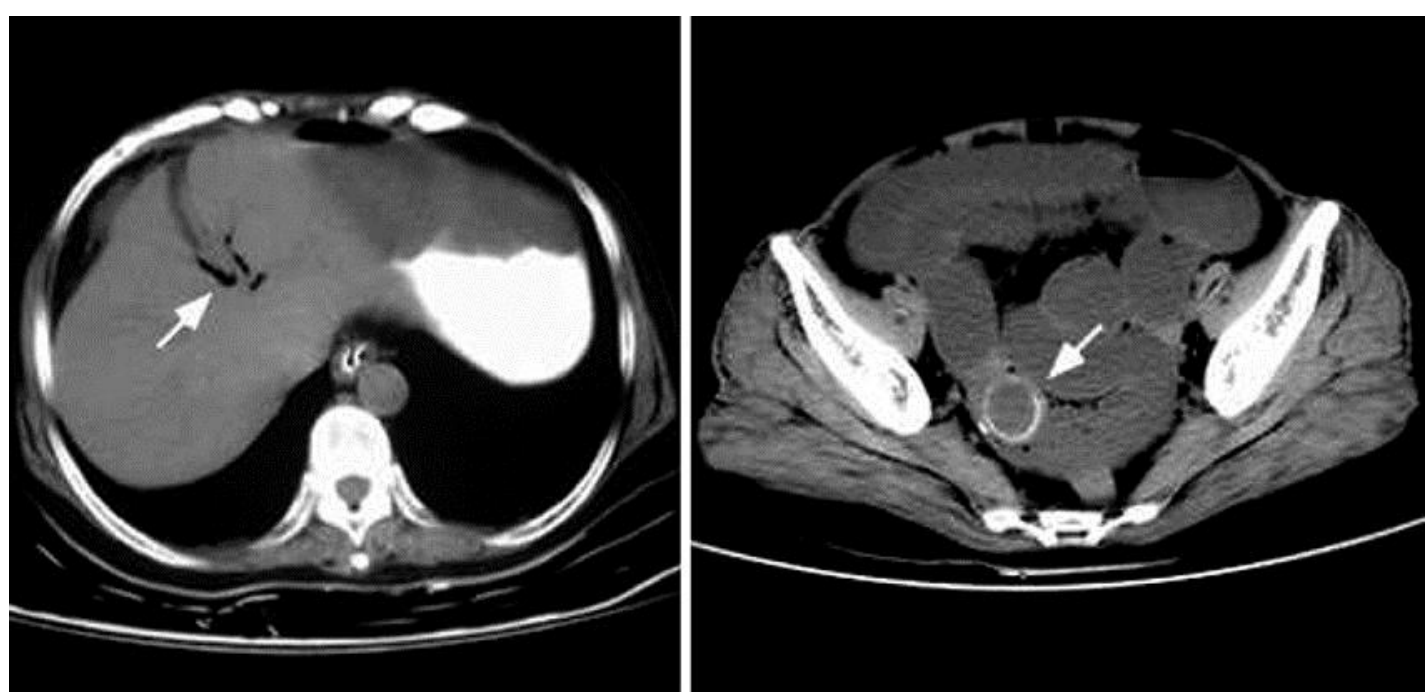

Fig. 3. CT scans showing pneumobilia (arrow in the picture on the left) and calcified gallstone lodged in proximal jejunum (arrow in the picture on the right). 


\begin{tabular}{ll|l} 
Case Reports in & $\begin{array}{l}\text { Case Rep Gastroenterol 2017;11:389-395 } \\
\text { Gastroenterology }\end{array}$ & $\begin{array}{l}\text { DO } 2017 \text { The Author(s). Published by S. Karger AG, Basel } \\
\text { www.karger.com/crg }\end{array}$ \\
\cline { 2 - 3 } & Abich et al.: Gallstone Ileus: An Unlikely Cause of Mechanical Small Bowel Obstruction
\end{tabular}

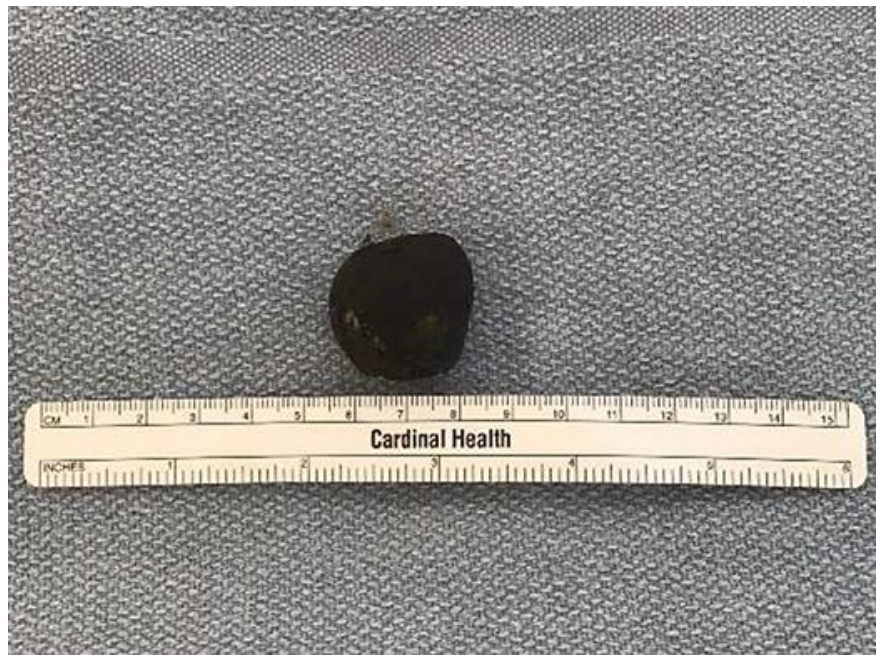

Fig. 4. Gallstone milked from proximal jejunum measuring $2.5 \mathrm{~cm}$ in diameter. 